\title{
Software para Pré-Dimensionamento de Aterro Sanitário pelo Método Das Trincheiras Destinado a Municípios de Pequeno Porte
}

\author{
Software for Pre-Design of Landfill by Method Intended from the Trenches of \\ Smaller Municipalities
}

Layara de Paula Sousa Santos', Thiago Augusto Mendes², Gustavo Rodrigues de Oliveira Abreu ${ }^{3}$, Agenor Sousa Santos Neto ${ }^{4}$ e Valéria de Sousa Leitão ${ }^{5}$

${ }^{1}$ Universidade Federal de Goiás, Goiás, Brasil

2, 4,5 Pontifícia Universidade Católica de Goiás

${ }^{3}$ Instituto Federal de Educação, Ciência e Tecnologia de Goiás

\begin{abstract}
Resumo
O trabalho teve como principal finalidade subsidiar elementos de projeto e gestão para o desenvolvimento de aplicativo computacional envolvendo o pré-dimensionamento de aterros sanitários pelo método das trincheiras destinados a municípios de pequeno porte. A ferramenta computacional (software) desenvolvida em linguagem Java necessita de dados de entrada que devem ser fornecidos pelo usuário para que se processe os cálculos para disposição do lixo urbano e de saúde em aterros sanitários executados pelo método das trincheiras. Após a entrada dos dados pelo o usuário, clica-se sobre o botão "CALCULAR" do software, então os cálculos, tabelas e gráficos de saída são processados e já podem ser visualizados e analisados. Os resultados de pré-dimensionamento para diferentes cenários (dados de entrada) obtidos foram satisfatórios visto que apresentaram validade se comparados com o roteiro de cálculo estabelecido pelas diversas referências acadêmicas da área como Kroetz (2003) e Ferreira (2008).

Palavras-chave: Aterros Sanitários. Método das Trincheiras. Municípios de Pequeno Porte. Ferramenta Computacional. PréDimensionamento.
\end{abstract}

\begin{abstract}
The work was mainly intended to subsidize design elements and management to develop computer application involving the preliminary design of landfills by the method of the trenches for the small municipalities. The computational tool (software) developed in Java requires input data to be supplied by the user so that it processes the calculations for disposal of urban waste and health in landfills run by the method of the trenches. After the entry of data by the user, click on the button "CALCULATE" of the software, then calculations, tables and graphics output is processed and can now be viewed and analyzed. The results of preliminary design for different scenarios (input data) obtained were satisfactory as presented validity compared with the calculation script established by the different academic references of the area as Kroetz (2003) and Ferreira (2008).
\end{abstract}

Keywords: Landfills. Method from the Trenches. Small Porte municipalities. Computational tool. Pre-Sizing. 


\title{
1 Introdução
}

Segundo pesquisas realizadas pela Associação Brasileira de Empresas de Limpeza Pública e Resíduos Especiais (ABRELPE), a geração de resíduos sólidos urbanos (RSU) no Brasil obteve um aumento de 4,1\% de 2012 para 2013, índice que é superior à taxa de crescimento populacional urbano no país, que no período foi de $3,7 \%$. O índice de $58,3 \%$ correspondente à destinação final adequada no ano de 2013 permaneceu praticamente constante, porém a quantidade de RSU destinada inadequadamente cresceu em relação ao ano anterior, totalizando 28,8 milhões de toneladas que seguiram para lixões ou aterros controlados (ABRELPE, 2013, p.28).

Dessa forma, percebe-se que grande parte dos municípios brasileiros pode estar dispondo os RSU gerados de forma desorganizada e desestruturada. Esta prática gera graves consequências como a contaminação do solo, do ar, das águas superficiais e subterrâneas, além da transmissão de doenças, com impactos agravantes na saúde pública. Verifica-se ainda que, o gerenciamento inadequado desses resíduos em locais que na maioria das vezes não possui licenciamento, utiliza como critério de disposição final a disponibilidade de áreas e a distância em relação aos centros urbanos, ocorrendo a céu aberto (SCHALCH et al., 2002, p.1).

O manejo inadequado de resíduos sólidos prejudica a economia impossibilitando a reutilização e a coleta seletiva, onde a reciclagem assegura a valorização econômica na transformação de determinados materiais. O processo de compostagem, por exemplo, pode ser outra forma de garantir empregos, reduzir a desigualdade social e melhorar a qualidade ambiental, produzindo adubos corretivos de boa qualidade para o solo.

Em municípios de pequeno porte, devido à pequena quantidade de resíduos gerados diariamente, é possível pensar-se em sistemas de disposição final simples, como a operação em trincheiras. Segundo o Programa de Pesquisas em Saneamento Básico (PROSAB, 1999 apud KROETZ, 2003, p.3) são considerados municípios de pequeno porte aqueles com até 20.000 habitantes. Devido à escassez de recursos, falta de profissionais especializados na área de resíduos e estrutura técnica inadequada, as pequenas comunidades e prefeituras de cidades de pequeno porte enfrentam dificuldades com relação à disposição dos resíduos sólidos urbanos.

Nesse contexto, o objetivo da pesquisa é oferecer subsídios para o desenvolvimento de um sistema de pré-dimensionamento automatizado de aterros sanitários executados pelo método das trincheiras para municípios de pequeno porte (até 20.000 habitantes). Objetivo este que se completa com o desenvolvimento e implementação de uma ferramenta computacional (software) em Java para avaliar os diferentes cenários de entrada (particularidades de cada município) e sugestão de prédimensionamento do aterro sanitário pelo método das trincheiras, uma vez que facilita consideravelmente a análise dos estudos para que os RSU sejam dispostos adequadamente.

\section{Aterros sanitários}

Segundo a NBR 8419 "Apresentação de Projetos de Aterros Sanitários de Resíduos Sólidos Urbanos" da ABNT NBR 8419:2002 (ABNT, 1992):

\begin{abstract}
Os aterros sanitários são definidos como técnica de disposição de resíduos sólidos urbanos no solo, sem causar danos à saúde púbica, minimizando os impactos ambientais. Este método consiste na utilização princípios de engenharia para confinar os resíduos sólidos a menor área possível e reduzi-los ao menor volume permissível, cobrindo-os com uma camada de terra na conclusão de cada jornada de trabalho, ou a intervalos menores, se necessário (1992, p.1).
\end{abstract}

A disposição de resíduos sólidos em aterros sanitários como forma de destinação final, é vista como a solução mais econômica, quando comparado com outros processos como a incineração (MANSOR et al., 2010, p. 32). Portanto, se constitui como o método mais viável no que se refere às condições econômicas dos municípios de pequeno porte. 
A construção de aterros sanitários envolve técnicas de engenharia e normas operacionais específicas, permitindo o confinamento de grande volume de RSU em áreas menores, tendo como prioridades o controle de poluição ambiental e proteção à saúde pública. Portanto devem seguir padrão estabelecido pelas leis vigentes, quanto à construção, disposição e operação, considerando que um aterro desestruturado perde a característica do aspecto sanitário e se torna um lixão ou depósito a céu aberto (PROSAB, 1999, p. 18).

Outro fator preocupante é a formação de percolados, durante a decomposição anaeróbia. O chorume pode contaminar as águas superficiais e subterrâneas, caso infiltrar-se no solo. Segundo Luz (1981), pode-se definir "chorume" como o líquido proveniente da decomposição de resíduos, provenientes de três fontes:

- umidade natural dos resíduos, que se agrava sensivelmente nos períodos chuvosos;

- da água de constituição orgânica, que sobra durante a decomposição;

- líquidos provenientes da dissolução da matéria orgânica pelas enzimas expelidas pelas bactérias.

\subsection{Aterro sanitário executado pelo método das trincheiras como sistema de disposição final}

Os elementos de projeto, no caso das trincheiras são a seguir descritos segundo modelos proposto por Gomes e Martins (2002, p. 63):

- sistema de drenagem superficial: O sistema de drenagem superficial tem a função de evitar a entrada de água de escoamento superficial. Os escoamentos de águas superficiais aumentam o volume de lixiviados, além de facilitar o surgimento de erosões, este problema pode causar a destruição da camada e cobertura de taludes. Para a definição do local e dimensionamento do sistema de drenagem superficial, é necessária a consecução de dados obtidos nos levantamentos topográficos e climatológicos.

- sistema de drenagem de lixiviados: Nos municípios de pequeno porte normalmente ocorre uma geração bastante baixa de chuva, ainda assim, torna-se necessário executar um sistema específico para o tratamento desses líquidos. O certo é que a qualidade do lixiviado gerado corresponde a um efluente altamente poluidor e que não poderá ser descartado no meio ambiente. A legislação ambiental inclui parâmetros máximos para o lançamento de efluentes nos recursos hídricos naturais.

- impermeabilização de fundo e de laterais: As trincheiras deverão conter os resíduos aterrados e os líquidos gerados, sem permitir a poluição ambiental. Para isso deverá ser projetado sistema de impermeabilização de laterais e fundos.

- sistema de drenagem de gases: Com a degradação dos resíduos dentro das trincheiras, pelos microrganismos anaeróbios, formam-se gases, principalmente metano e dióxido de carbono. Para evitar o acúmulo exagerado de gases dentro das trincheiras, o que poderá gerar incêndios locais, além de ocupar área dos resíduos, é necessário projetar-se um sistema de drenagem de gases. Geralmente, esse sistema é disposto tanto na vertical, como na horizontal, tendo em vista a interação entre os resíduos e o tamanho da trincheira.

- cobertura intermediária e final: O sistema de cobertura tem a função de eliminar a proliferação de vetores, diminuir a taxa de formação de lixiviados, reduzir a exalação de odores e impedir a saída descontrolada do biogás para a atmosfera.

\subsection{Seleção da área}

A seleção da área de construção de um aterro faz parte dos estudos preliminares para elaboração de um projeto de aterro sanitário em município de pequeno porte. De acordo com Paiva (2005, p.19) a seleção de áreas para aterros sanitários envolvem critérios técnicos, ambientais, econômicos, legais e sociais. Durante a escolha, devem-se considerar parâmetros que minimizem a possibilidade de existência de impactos ambientais negativos, levando em consideração fatores como clima, solos, hidrogeologia e geotecnia.

O geoprocessamento é uma ferramenta moderna capaz de facilitar e agilizar a seleção de áreas para disposição final de resíduos sólidos, onde se observa importante melhora na qualidade dos resultados. A área de conhecimento em questão utiliza na manipulação de informação georreferenciada diferentes 
técnicas, instrumentos, hardware e software, de forma a coletar, armazenar e processar dados geocodificados (GOMES e MARTINS, 2002, p.55).

São utilizados critérios de escolha da área de implantação de aterros, dentre esses, são considerados critérios ambientais, de uso e ocupação do solo e critérios operacionais, com objetivo de estabelecer coerência com a gestão do município em questão.

\subsection{Sistemas de operação de aterros sanitários}

De acordo com D'Almeida e Vilhena (2000 apud DENARDIN, 2013, p. 16), o processo de aterramento pode ser executado sob uma das três formas tradicionalmente empregadas: método da trincheira ou vala, método da rampa e método da área. A seguir, esses métodos são descritos, como:

- método da trincheira ou vala: Consiste na abertura de valas, onde o resíduo é disposto, compactado e posteriormente coberto com solo. As valas podem ser de pequena (operação manual) ou de grandes dimensões, permitindo a entrada de equipamentos maiores em seu interior;

- método da rampa: Conhecido também como método da escavação progressiva é fundamentado na escavação da rampa, onde o resíduo é disposto e compactado pelo trator e posteriormente coberto com solo. Normalmente, esse método é empregado em áreas de meia encosta, onde o solo natural ofereça boas condições para ser escavado e posteriormente possa ser utilizado como material de cobertura.

- método da área: É frequentemente empregado em locais de topografia plana e lençol freático raso.

A pesquisa é focada no dimensionamento de aterros sanitários pelo método das trincheiras, tendo em vista que possui pequenas dimensões e é destinado a um município de pequeno porte.

\subsection{Dimensionamento das principais estruturas do aterro segundo o método das trincheiras}

Algumas dimensões das trincheiras devem ser pré-estabelecidas, em decorrência de limitações operacionais. A largura das trincheiras na superfície não deve exceder três metros ABNT NBR 15 849:2010 (ABNT, 2010). Se a largura for superior a três metros, atividades como a descarga de veículos e cobertura dos resíduos com terra serão dificultadas, colocando em risco a qualidade operacional do aterro. A profundidade também não deverá exceder três metros porque profundidades maiores comprometem a estabilidade da trincheira. $\mathrm{O}$ comprimento é decorrente do volume da trincheira. Tendo-se o volume de lixo a ser aterrado, com a profundidade e a largura pré-fixadas, obtém-se o comprimento da trincheira (KROETZ, 2003, p.32).

Segundo (GOMES e MARTINS, 2002, p. 69), para o dimensionamento das trincheiras é necessário adotar os seguintes passos:

- verificar a quantidade de resíduos que será encaminhada diariamente para a disposição final;

- adotar cobertura intermediária de 10 a $20 \mathrm{~cm}$ de solo local, com compactação média (250 a 350 $\mathrm{kg} / \mathrm{m}^{3}$ ) ou $25 \%$ do volume de resíduos a serem aterrados;

- adotar a vida útil da trincheira (a sugestão é de 2 a 4 meses);

- decidir a compactação a ser realizada no aterramento dos resíduos (sem compactação a densidade média dos resíduos é da ordem de 100 a $150 \mathrm{~kg} / \mathrm{m}^{3}$; para uma compactação manual: 250 a $\left.350 \mathrm{~kg} / \mathrm{m}^{3}\right)$;

- adotar a profundidade da trincheira, levando em consideração o nível do lençol freático e camada de solo;

- definir a forma da trincheira e adotar uma das dimensões, por exemplo, a largura da trincheira;

- calcular a outra dimensão, visto que o comprimento das trincheiras é decorrente do volume total de lixo, profundidade da trincheira, largura superior, e largura inferior.

\subsection{Canais de drenagem de águas pluviais}

O método conhecido como "Método Racional" é usado para calcular a vazão de pico de uma determinada bacia hidrográfica (bacia de contribuição), considerando uma seção de estudo.

A fórmula racional utilizada pode ser visualizada pela Equação 1: 


$$
Q=\frac{\text { C.I.A }}{360}
$$

onde, $Q$ é a vazão de pico em $\mathrm{m}^{3} / \mathrm{s}$; $C$ é o coeficiente de escoamento superficial ou de deflúvio, função de características da bacia, adimensional; $I$ é a intensidade da precipitação em $\mathrm{mm} /$ hora e $A$ é a área total da bacia de drenagem em $\mathrm{km}^{2}$.

O método racional é amplamente utilizado na literatura para a determinação de vazões de pico em pequenas bacias. A grande aceitação deste está relacionada à simplicidade de sua utilização e a obtenção de resultados satisfatórios, desde que respeitadas às condições de validade (CSOBI, 2011, p.11).

\subsection{Impermeabilização}

Segundo a Fundação Estadual do Meio Ambiente (FEAM, 2006, p.16) a camada de impermeabilização da base deve garantir a segura separação da disposição de resíduos do subsolo, impedindo a contaminação do lençol freático e do meio natural devido à ocorrência advindas de substâncias tóxicas.

Para desempenhar essa função de maneira eficiente, a camada de impermeabilização de materiais deve compor-se de solo argiloso de baixa permeabilidade ou geomembrana sintética de espessura adequada.

De acordo com Gomes e Martins (2002, p. 77), no projeto de estruturas de base e cobertura em aterros sanitários, o emprego de geomembranas deve considerar:

- a seleção do material da geomembrana;

- a preparação do subleito;

- o transporte, armazenamento e colocação da geomembrana;

- a qualidade das emendas.

Geomembranas do tipo Polietileno de Alta Densidade (PEAD) apresentam excelente resistência a ataques químicos a custos razoáveis. No entanto, são mais difíceis de soldar. Uma alternativa destacada pelos autores são as membranas de Cloreto de Polivinil (PVC) e de polipropileno, porque estes materiais apresentam excelente resistência mecânica, mas baixa resistência química.

\subsection{Sistema de cobertura}

Segundo a Associação Brasileira de Normas Técnicas - ABNT NBR 8419:2002 (ABNT, 2002), o sistema de cobertura final de aterros deve minimizar a infiltração de água no aterro, exigir pouca manutenção, promover a drenagem, não estar sujeito a erosão e possuir um coeficiente de permeabilidade inferior ao solo natural da área do aterro. Deve-se também indicar o tipo de impermeabilização adotado e os materiais empregados, com suas especificações e características segundo as correspondentes normas brasileiras.

A Figura 1a representa o sistema de cobertura com manta PVC em solo compactado e a Figura 1b representa o sistema de cobertura telhado móvel, utilizado devido ausência de cobertura intermediária e quando o município apresenta elevados índices de precipitação. 


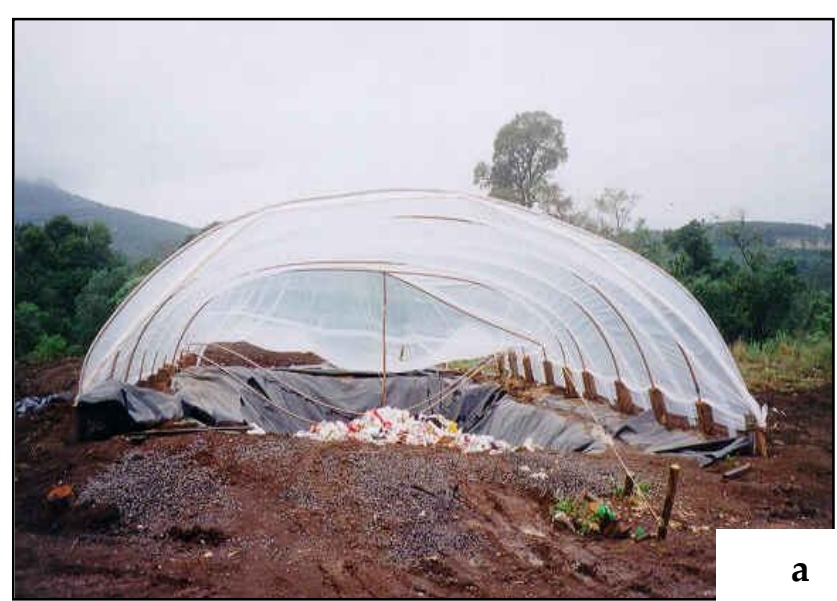

Figura 1 (a) - Sistema de cobertura com manta PVC Fonte: (Prosab, 2003)

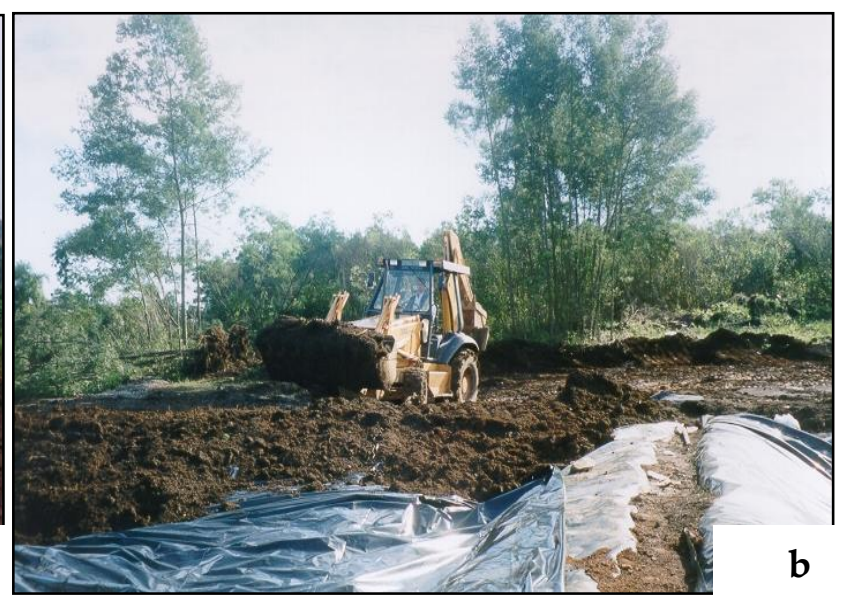

Figura 1 (b) - Sistema de cobertura com telhado móvel Fonte: (Prosab, 2003)

\subsection{Sistema de drenagem de lixiviados}

É necessário conhecer o balanço hídrico de um aterro sanit

ário porque este pode influenciar o dimensionamento do sistema de drenagem de líquidos. Medeiros et al. (2002, p. 39) citam que uma correta previsão da produção desses líquidos é importante para o projeto do sistema de drenagem de lixiviados produzidos nos aterros sanitários, e até mesmo para técnicas operacionais, como a recirculação de líquidos que é uma prática adotada em alguns aterros.

A Figura 2 exemplifica uma tubulação para captação do lixiviado que passa pela manta PEAD por meio de um flange. Constitui-se em sistema de impermeabilização, no qual é finalizado dentro de um poço de captação, localizado preferencialmente no ponto mais baixo do terreno, sem a necessidade de bombeamento.

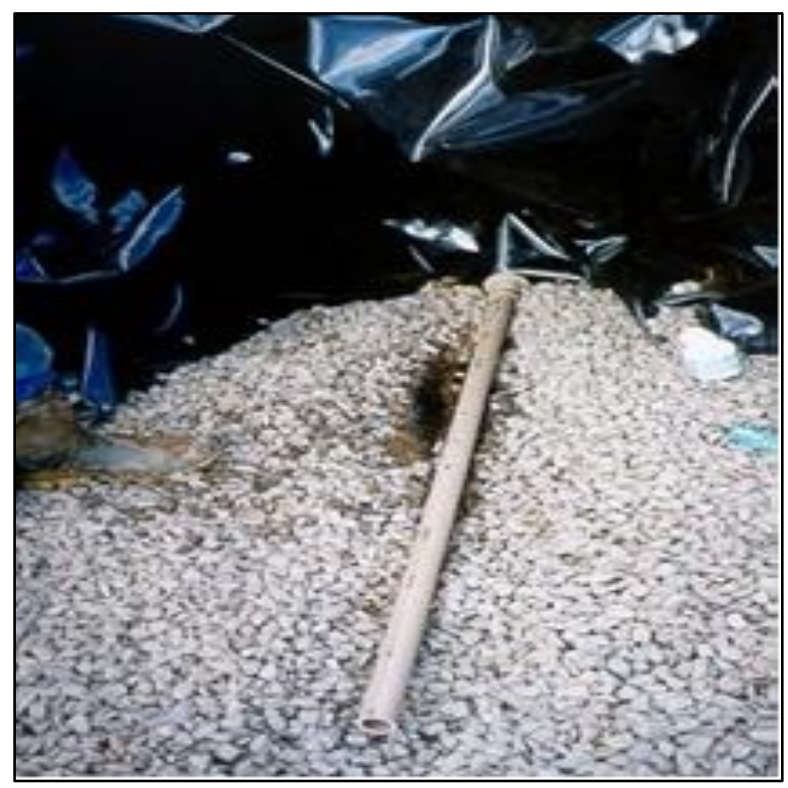

Figura 2 - Tubulação perfurada entre a brita para coleta de lixiviado.

Fonte: (Prosab, 2003)

\subsection{Sistema de drenagem de gases}

Os drenos de gases devem ser dispostos de preferência sobre a rede de drenagem de lixiviados, atravessando verticalmente o aterro até a sua superfície, configurando chaminés de exaustão. 
Tradicionalmente, essas "chaminés" são conformadas com manilhas drenantes de concreto armado perfuradas. Outra opção seria a escolha de materiais como pneus, tambores de óleo e garrafas PET coletadas no próprio aterro, as quais devem ser perfuradas e preenchidas com brita oํ 2. Também, devido à baixa geração, são previstos queimadores de gases, dispostos nas extremidades superiores das chaminés, com a finalidade de possibilitar a queima controlada dos gases (GOMES e MARTINS, 2002, p. 88).

Após todo o levantamento dos dados necessários para subsidiar o desenvolvimento da ferramenta computacional, optou-se por não dimensionar os elementos de drenagem e impermeabilização pela dificuldade de simulação e diversidade de materiais.

\section{Material e Métodos}

Primeiramente foi necessário promover uma ampla pesquisa bibliográfica sobre dimensionamento de aterros sanitários pelo método das trincheiras, no intuito de identificar quais os dados de entrada seriam necessários para o pré-dimensionamento do aterro e posteriormente, desenvolver a ferramenta computacional.

Com todo embasamento teórico, foi possível subsidiar os elementos necessários para a operacionalização do software, começando pelo desenvolvimento e implantação das ferramentas de auxílio, gestão, dimensionamento e projeto.

A ferramenta computacional foi desenvolvida em linguagem Java, pois, permite desenvolver conceitos introdutórios de programação utilizando uma sintaxe simplificada, onde o usuário pode editar código Java, compilar, depurar e visualizar a execução do código. A tecnologia Java é gratuita, além de possuir portabilidade, onde o mesmo código Java roda em diversas plataformas sem a necessidade de alteração do código e as aplicações podem ser facilmente migradas entre servidores. Esta ferramenta permite que os dados sejam representados em vários formatos para exibição (binário, hexadecimal, entre outros), permite a visualização do histórico da execução do programa tanto na forma gráfica quanto na forma de texto.

Dentre as desvantagens de se trabalhar com a ferramenta Java, pode-se destacar a demanda de tempo exigida na pré-compilação. Outro aspecto negativo é que o padrão Java tem uma especificação rígida do funcionamento de tipos numéricos. Essa especificação não condiz com a implementação de pontos flutuantes na maioria dos processadores, o que faz com que a ferramenta seja significantemente mais lenta quando é utilizado bastante processamento numérico. Ainda assim, o mesmo pode ser utilizado em desktops. Diante disso, pode-se verificar que as vantagens são maiores que as desvantagens e por isso a tecnologia Java é amplamente utilizada.

Depois de implantada (desenvolvida) a ferramenta computacional, a mesma foi validada e verificada com dados de entrada (dados de projeto) de Kroetz (2003, p. 142) e Ferreira (2008).

Kroetz (2003, p. 70) utilizou uma ferramenta computacional denominada SADES, utilizada para auxiliar o dimensionamento de aterros em trincheiras para municípios de pequeno porte. O usuário pode escolher a opção desejada, como o cadastramento de novas áreas para utilização do sistema de apoio à decisão em escolhas de áreas e dimensionamento das principais estruturas do aterro sanitário.

Utilizando-se dos dados técnicos (de projeto) de Ferreira (2008) foi possível utilizá-los como dados de entrada para a verificação e validação da ferramenta e avaliar os resultados de saída (prédimensionamento do aterro pelo método das trincheiras).

\section{Resultados}

Dentre os dados que subsidiam o pré-dimensionamento de aterros sanitários, destacam-se a seleção da área, método de aterramento, inclinação, compactação, dimensionamento das principais estruturas do aterro, determinação de vazões, impermeabilização, sistema de cobertura, sistema de drenagem de lixiviados e sistema de drenagem de gases. Com o levantamento, obtenção e inclusão destes dados de entrada no software desenvolvido, a ferramenta computacional previamente os verifica (se não há restrições) e para logo em seguida, estar apta a prosseguir com os cálculos 
necessários para o pré-dimensionamento. A Figura 3 mostra como é a tela principal do software desenvolvido em Java e a Figura 4 os dados de entrada necessários para que a ferramenta computacional processe o pré-dimensionamento do aterro sanitário pelo método das trincheiras.

\section{Dimensionamento de Aterros Sanitários}

Dimensione aterros sanitários pelo método das trincheiras, calculando a população por juros compostos, usando esse aplicativo. Esse aplicativo funciona tanto em computadores de mesa quanto portáveis, além de não usar internet para realizar os cálculos. dessa forma podendo funcionar mesmo sem nenhuma conexão, em qualquer lugar.

\section{Comece agora}

Saiba mais

Figura 3 - Tela de abertura da ferramenta computacional desenvolvida em Java.

Fonte: Autores (2015).

E Início / Dados/Resultados

Resíduos a serem aterrados

Nas trincheiras:

Tipo

\begin{tabular}{|c|c|}
\hline Lixo urbano & $\checkmark$ \\
\hline \multicolumn{2}{|c|}{ Quantidade de resíduo } \\
\hline 0.80 & $\mathrm{~kg} / \mathrm{hab}$ /dia \\
\hline \multicolumn{2}{|c|}{ Índice de inclinação } \\
\hline $1 / 1$ & $h / v$ \\
\hline
\end{tabular}

Distância mínima do lençol freático exigida pela legislação:

\begin{tabular}{l|l}
6.00 & $\mathrm{~m}$
\end{tabular}

Dados do projeto:

Município

Cidade Exemplo

População atual

25000 hab

Taxa de crescimento anual da população:

\begin{tabular}{l|l}
\hline 1.40 & $\%$
\end{tabular}

Profundidade crítica do lençol freático no final da estação chuvosa:

\begin{tabular}{|l|l|}
\hline 11.00 & $\mathrm{~m}$ \\
\hline
\end{tabular}

Área do terreno

\begin{tabular}{|l|l|}
\hline 200000 & $\mathrm{~m}^{2}$
\end{tabular}

Requisito adicional de área

\begin{tabular}{|l|l}
\hline 40 & $\%$
\end{tabular}

Dimensão fixa do aterro

22

Carregar dados

Salvar formulári

Restaurar formulário
Nas valas sépticas:

Tipo

Resíduos dos serviços de sai $\square$

Quantidade de resíduo

5.0 g/hab./dia

Índice de inclinação

\begin{tabular}{l|l|l|}
\hline 11 & $h / \mathrm{v}$
\end{tabular}

Distância mínima do lençol freático exigida pela legislação:

\begin{tabular}{|l|l|}
\hline 8.00 & $\mathrm{~m}$
\end{tabular}

Método de aterramento

Trincheiras $\checkmark$

Alcance dos serviços de limpeza pública durante o horizonte de projeto

100

$\%$

Grau de compactação do lixo no aterro sanitário

\begin{tabular}{l|l}
$0.70 \quad t / m^{3}$ \\
\hline
\end{tabular}

Permeabilidade ao longo do perfil do solo

$0.00001 \quad \mathrm{~cm} / \mathrm{s}$

Intensidade pluviométrica crítica

$1650 \quad \mathrm{~mm} / \mathrm{ano}$

Horizonte de projeto

$20 \quad$ anos

Figura 4 - Tela principal de entrada dos dados que devem ser fornecidos pelo usuário para o pré-dimensionamento do aterro santário pelo método das trincehira

Fonte: Autores (2015)

REGET - V. 20, n. 1, jan.- abr. 2016, p.405-416 
Após a entrada dos dados pelo o usuário e a ação sobre o botão "CALCULAR" da ferramenta computacional (Figura 4), os cálculos são processados e tanto os gráficos de saídas (estimativas de população e o pré-dimensionamento das trincheiras - geometria) e as tabelas (volumes de solo seco, compactado e áreas) já podem ser visualizadas. A Figura 5 mostra uma das formas de se visualizar estes dados de saídas (em forma de tabela).

\begin{tabular}{|c|c|c|c|c|c|c|c|c|c|c|c|}
\hline \multirow[b]{2}{*}{ Ano } & \multicolumn{11}{|c|}{ Planilha de Cálculo para disposição do Serviço Urbano } \\
\hline & $\begin{array}{l}\text { Pop. } \\
\text { urbana } \\
\text { (hab) }\end{array}$ & $\begin{array}{l}\text { Quantidade } \\
\text { gerado } \theta \\
\text { coletado } \\
\text { (trano) }\end{array}$ & $\begin{array}{l}\text { Volume } \\
\text { compactado } \\
\text { dlsposto no } \\
\text { aterro (mªno) }\end{array}$ & $\begin{array}{l}\text { Volume } \\
\text { compactado } \\
\text { dlaposto no } \\
\text { aterro ( } \mathrm{m}^{2} / \mathrm{dla} \text { ) }\end{array}$ & $\begin{array}{l}\text { Volume de solo } \\
\text { de } \\
\text { recobrimento } \\
\text { (mªno) }\end{array}$ & $\begin{array}{l}\text { Volume desolo } \\
\text { de } \\
\text { recobrimento } \\
\left(\mathrm{m}^{2} / \mathrm{d} \text { dla }\right)\end{array}$ & $\begin{array}{l}\text { Volume } \\
\text { total de } \\
\text { operaç3o do } \\
\text { aterro } \\
\left(m^{2} / a n o\right)\end{array}$ & $\begin{array}{l}\text { Volume } \\
\text { total de } \\
\text { operaçao do } \\
\text { aterro } \\
\text { (mindia) }\end{array}$ & $\begin{array}{l}\text { Volume de } \\
\text { operaçao } \\
\text { acumulado no } \\
\text { aterro }\left(m^{1}\right)\end{array}$ & $\begin{array}{l}\text { Volume } \\
\text { acumulado } \\
\text { das } \\
\text { trincheiras } \\
\left\langle\mathrm{m}^{2}\right\rangle\end{array}$ & $\begin{array}{l}\text { Area } \\
\text { superticlal } \\
\text { acumulada } \\
\text { pelas } \\
\text { trincheiras } \\
\left(\mathrm{m}^{2}\right)\end{array}$ \\
\hline 2015 & 25000 & 0.00 & 0.00 & 0.00 & 0.00 & 0.00 & 0.00 & 0.00 & 0.00 & 0.00 & 0.00 \\
\hline 2016 & 25350 & 7402.20 & 10574.57 & 28.97 & 2114.91 & 5.79 & 12689.49 & 34.77 & 12689.49 & 14527.78 & 3870.13 \\
\hline 2017 & 25705 & 7505.83 & 10722.62 & 29.38 & 2144.52 & 5.88 & 12867.14 & 35.25 & 25556.62 & 29055.56 & 7740.26 \\
\hline 2018 & 26065 & 7610.91 & 10872.73 & 29.79 & 2174.55 & 5.96 & 13047.28 & 35.75 & 38603.90 & 43583.34 & 11610.39 \\
\hline 2019 & 26430 & 7717.47 & 11024.95 & 30.21 & 2204.99 & 6.04 & 13229.94 & 36.25 & 51833.84 & 58111.12 & 15480.53 \\
\hline 2020 & 26800 & 7825.51 & 11179.30 & 30.63 & 2235.86 & 6.13 & 13415.16 & 36.75 & 65249.00 & 72638,90 & 19350.66 \\
\hline 2021 & 27175 & 7935.07 & 11335.81 & 31.06 & 2267.16 & 6.21 & 13602.97 & 37.27 & 78851.97 & 87166.69 & 23220.79 \\
\hline 2022 & 27555 & 8046.16 & 11494.51 & 31.49 & 2298.90 & 6.30 & 13793.41 & 37.79 & 92645.39 & 101694.47 & 27090.92 \\
\hline 2023 & 27941 & 8158.80 & 11655.43 & 31.93 & 2331.09 & 6.39 & 13986.52 & 38.32 & 106631.91 & 116222.25 & 30961.05 \\
\hline 2024 & 28332 & 8273.03 & 11818.61 & 32.38 & 2363.72 & 6.48 & 14182.33 & 38.86 & 120814.24 & 130750.03 & 34831.18 \\
\hline 2025 & 28729 & 8388.85 & 11984.07 & 32.83 & 2396.81 & 6.57 & 14380.89 & 39.40 & 135195.13 & 145277.81 & 38701.32 \\
\hline 2026 & 29131 & 8506.29 & 12151.85 & 33.29 & 2430.37 & 6.66 & 14582.22 & 39.95 & 149777.34 & 159805.59 & 42571.45 \\
\hline 2027 & 29539 & 8625.38 & 12321.97 & 33.76 & 2464.39 & 6.75 & 14786.37 & 40.51 & 164563.71 & 174333.37 & 46441.58 \\
\hline 2028 & 29953 & 8746.14 & 12494.48 & 34.23 & 2498.90 & 6.85 & 14993.38 & 41.08 & 179557.09 & 188861.15 & 50311.71 \\
\hline 2029 & 30372 & 8868.58 & 12669.40 & 34.71 & 2533.88 & 6.94 & 15203.28 & 41.65 & 194760.37 & 203388.93 & 54181.84 \\
\hline 2030 & 30797 & 8992.74 & 12846.78 & 35.20 & 2569.36 & 7.04 & 15416.13 & 42.24 & 210176.51 & 217916.71 & 58051.97 \\
\hline 2031 & 31228 & 9118.64 & 13026.63 & 35.69 & 2605.33 & 7.14 & 15631.96 & 42.83 & 225808.46 & 232444.49 & 61922.10 \\
\hline 2032 & 31665 & 9246.30 & 13209.00 & 36.19 & 2641.80 & 7.24 & 15850.80 & 43.43 & 241659.27 & 246972.27 & 65792.24 \\
\hline 2033 & 32109 & 9375.75 & 13393.93 & 36.70 & 2678.79 & 7.34 & 16072.72 & 44.03 & 257731.98 & 261500.06 & 69662.37 \\
\hline 2034 & 32558 & 9507.01 & 13581.44 & 37.21 & 2716.29 & 7.44 & 16297.73 & 44.65 & 274029.72 & 276027.84 & 73532.50 \\
\hline 2035 & 33014 & 9640.11 & 13771.58 & 37.73 & 2754.32 & 7.55 & 16525.90 & 45.28 & 290555.62 & 290555.62 & 77402.63 \\
\hline
\end{tabular}

Figura 5 - Dados de saída para disposição do lixo urbano para o horizonte de projeto de 20 anos utilizando os dados de entrada de Ferreira (2008). Fonte: Autores (2015)

Pode-se gerir preliminarmente o que há de necessidade para implantação de pequenos aterros sanitários pelos usuários, preferencialmente gestores de pequenos municípios, mudando o cenário e condições iniciais para novos processamentos.

A Quadro 1 mostra os dados de entrada utilizados (Ferreira, 2008) na verificação da ferramenta computacional desenvolvida para o processamento dos cálculos do aterro sanitário para disposição do lixo urbano.

Utilizando-se a ferramenta computacional desenvolvida, também é possível verificar a geometria (tamanho das trincheiras) para disposição dos resíduos sólidos urbanos e também a célula diária de disposição. A Figura 6 mostra os diagramas dos elementos citados anteriormente.

Por meio dos dados de entrada utilizados, foi possível obter o pré-dimensionamento que poderá auxiliar a gestão, projeto e manutenção de pequenos aterros sanitários em pequenos municípios (menores que 20.000 habitantes).

Os resultados de pré-dimensionamento obtidos por meio da ferramenta computacional desenvolvida foram satisfatórios visto que a mesma apresentou validade se comparada com o roteiro de cálculo estabelecido por Ferreira (2008). 
Quadro 1 - Dados de entrada utilizados para verificação da ferramenta computacional desenvolvida (Pré-dimensionamento de aterro sanitário utilizando o método das trincheiras)

\begin{tabular}{|l|c|l|c|}
\hline População: & 20.000 habitantes & Inclinação: & $1 / 1$ \\
\hline $\begin{array}{l}\text { Taxa de crescimento anual da } \\
\text { população: }\end{array}$ & $1,40 \%$ & $\begin{array}{l}\text { Distância mínima do lençol } \\
\text { freático: }\end{array}$ & $6,00 \mathrm{~m}$ \\
\hline $\begin{array}{l}\text { Profundidade crítica do lençol } \\
\text { freático: }\end{array}$ & $11,00 \mathrm{~m}$ & $\begin{array}{l}\text { Grau de compactação do lixo } \\
\text { no aterro sanitário: }\end{array}$ & $0,70 \mathrm{t} / \mathrm{m}^{3}$ \\
\hline Área do terreno: & $200000 \mathrm{~m}^{2}$ & $\begin{array}{l}\text { Permeabilidade ao longo do } \\
\text { perfil do solo: }\end{array}$ & $0,00001 \mathrm{~cm} / \mathrm{s}$ \\
\hline Requisito adicional de área: & $40 \%$ & $\begin{array}{l}\text { Intensidade pluviométrica } \\
\text { crítica: }\end{array}$ & $1650 \mathrm{~mm} / \mathrm{ano}$ \\
\hline Dimensão fixa do aterro: & $22 \mathrm{~m}$ & Horizonte de projeto: & 20 anos \\
\hline Quantidade de RSU: & $‘, 8 \mathrm{~kg} / \mathrm{hab} /$ dia & \multicolumn{2}{|l}{} \\
\cline { 1 - 3 } & \multicolumn{2}{|l}{} &
\end{tabular}

Fonte: Ferreira (2008).

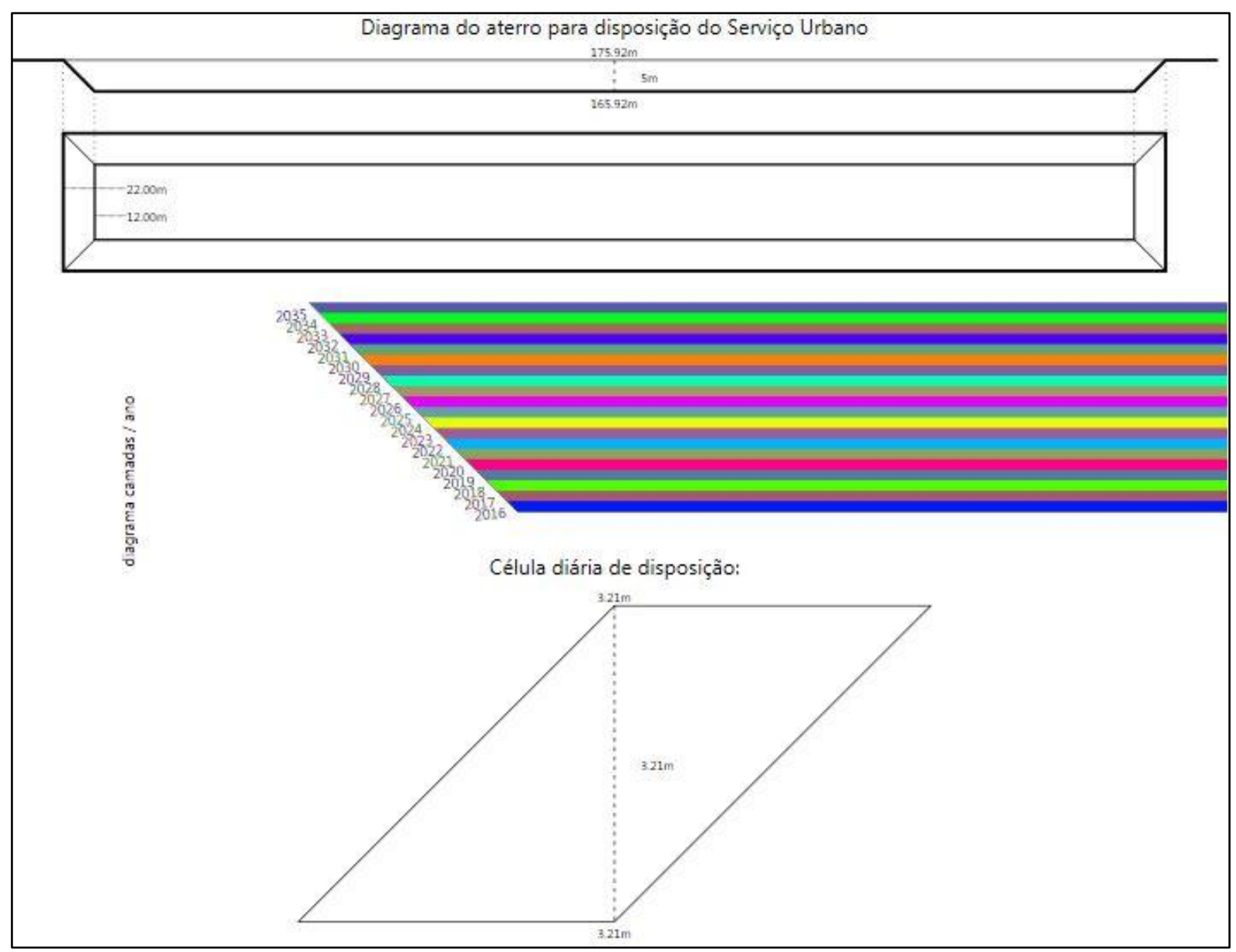

Figura 6 - Diagrama do aterro para disposição do serviço urbano

Fonte: Autores (2015)

Algumas das limitações da ferramenta computacional utilizada são as variações sofridas pelo material de cobertura ou pela degradação dos resíduos com o tempo que não foram consideradas, bem como às dificuldades de previsões de desempenho de longo prazo, devido à depreciação de materiais e estruturas. Outra limitação é a dificuldade de simulação dos sistemas de drenagem e impermeabilização. Para pesquisas futuras, sugere-se desenvolver a capacidade do modelo de simular 
a distribuição espacial e temporal da geração de lixiviados nestes aterros durante o processo de construção e operação e em certo período após o encerramento e também previsões de desempenho de materiais e estruturas ao longo do tempo.

\section{Conclusões}

Este trabalho representa a aplicação de direta da disciplina de modelagem na área da Engenharia Ambiental, especificamente na área de saneamento, que teve por finalidade subsidiar dados necessários para o desenvolvimento de uma ferramenta computacional que facilita o prédimensionamento de aterro sanitário executado pelo método das trincheiras. Com o fornecimento de dados iniciais (entrada), o cálculo é realizado de maneira simples, tanto para dispor resíduos sólidos urbanos, quanto para resíduos sólidos de serviços de saúde.

Os principais dados de entrada que subsidiam o desenvolvimento da ferramenta computacional para o pré-dimensionamento de aterro pelo método das trincheiras são: população, profundidade do lençol freático, área do terreno, quantidade de resíduos sólidos urbanos gerados por habitante-dia, inclinação, grau de compactação do aterro, permeabilidade do solo, intensidade pluviométrica crítica, sistema de drenagem de lixiviados, impermeabilização de fundos e laterais, sistema de drenagem de gases e a cobertura intermediária e final.

Para a implantação da ferramenta computacional, os sistemas de drenagem e impermeabilização não foram contemplados pela dificuldade de simulação e diversidade de materiais de impermeabilização utilizados ou que podem ser utilizados. Toda a ferramenta computacional foi desenvolvida na linguagem Java.

A construção e aplicação da ferramenta computacional desenvolvida foram perfeitamente viáveis, e envolveu planejamento, pesquisa e interação de diferentes áreas do conhecimento. A pesquisa é relevante do ponto de vista ambiental, técnico, econômico e social visto que pode ser uma ferramenta muito útil para municípios de pequeno porte, que recebem pequenos volumes diários de resíduos sólidos urbanos, os quais podem não possuir mão de obra técnica qualificada. Dessa forma, a ferramenta computacional desenvolvida pode ser inicialmente utilizada para avaliar o prédimensionamento da destinação correta dos resíduos sólidos urbanos pelas pequenas administrações públicas municipais.

O aplicativo desenvolvido ainda não está disponível para acesso, uma vez que será aprimorado para ser disponibilizado.

\section{Referências}

ABRELPE - ASSOCIAÇÃO BRASILEIRA DE EMPRESAS DE LIMPEZA PÚBLICA E RESÍDUOS ESPECIAIS. (2013). Panorama dos resíduos sólidos no Brasil 2013. São Paulo: Grappa Editora e Comunicação. Disponível em: <http://www.abrelpe.org.br/Panorama/panorama2013.pdf >. Acesso em 13 maio 2015.

ASSOCIAÇÃO BRASILEIRA DE NORMAS TÉCNICAS. (1992). NBR 8.419: Apresentação de projetos de aterros sanitários de resíduos sólidos urbanos, Rio de Janeiro.

ASSOCIAÇÃO BRASILEIRA DE NORMAS TÉCNICAS. (2010). NBR 15.849: Resíduos sólidos urbanos: aterros sanitários de pequeno porte - diretrizes para localização, projeto, implantação, operação e encerramento. Rio de Janeiro.

CSOBI, A. (2011). Amortecimento superficial nos sistemas de micro-drenagem em regiões de baixa declividade. Dissertação de Mestrado. Universidade de São Paulo. São Paulo/SP, 154 p. 
DERNADIN, G. P. (2013). Estudo dos Recalques do Aterro Sanitário da Central de Resíduos do Recreio - Minas do Leão/ RS. (Dissertação de Mestrado). Santa Maria/ RS. 92 p.

FEAM - FUNDAÇÃO ESTADUAL DO MEIO AMBIENTE. (2006). Orientações Básicas para a Operação de Aterro Sanitário / Fundação Estadual do Meio Ambiente. Belo Horizonte.

FERREIRA, O. M. (2008). Disciplina Tratamento de Resíduos Sólidos. (Notas de aulas). Escola de Engenharia, Engenharia Ambiental. Pontifícia Universidade Católica de Goiás. Goiânia, GO.

GOMES, L. P.; MARTINS, F. B. (2002). Projeto, implantação e operação de aterros sustentáveis de resíduos sólidos urbanos para municípios de pequeno porte. In: CASTILHOS JUNIOR, A. B. Projeto, implantação e operação de aterros sustentáveis de resíduos sólidos urbanos para municípios de pequeno porte. Rio de Janeiro, ABES, Projeto PROSAB, p. 51-105.

IPT - INSTITUTO DE PESQUISAS TECNOLÓGICAS. (2000). Lixo municipal: manual de gerenciamento integrado. 2o Edição. São Paulo: IPT/CEMPRE, 370 p.

KROETZ, C. E. (2003). Desenvolvimento de um Sistema de Apoio ao Dimensionamento e Estimativa de Custos de Aterros Sanitários em Trincheiras para Municípios de Pequeno Porte. (Dissertação de Mestrado). Florianópolis/ SC, 159 p.

LUZ, F. X. R. (1981). Aterro sanitário: características, limitações, tecnologia para a implantação e operação. São Paulo: CETESB, 30 p.

MANSOR, M. T. C.; CAMARÃO,T. C. R. C.; CAPELINI, M; KOVAKS, A.; FILET, M.; SANTOS, G. A.; SILVA, A. B.. (2010). Resíduos Sólidos. São Paulo: Governo do Estado de São Paulo, Secretaria do Meio Ambiente, Coordenadoria de Planejamento Ambiental. 147p. Disponível em: $<$ http://www.ambiente.sp.gov.br/wp-content/uploads/publicacoes/sma/6-ResiduosSolidos.pdf>, acessado em: 13 maio 2015.

MEDEIROS, P. A.; SILVA, J. D.; CASTILHOS JÚNIOR, A. B. (2002). Balanço Hídrico em aterros de resíduos sólidos urbanos escala experimental de laboratório. In: CASTILHOS JUNIOR, A. B.; LANGE, L. C.; GOMES, L. P.; PESSIN, N. (Org.). Alternativas de disposição de resíduos sólidos urbanos para pequenas comunidades. Rio de Janeiro: ABES / RiMa, p. 39-46.

PAIVA, I. E. P. de. (2004). Aterro Sanitário em Municípios de Pequeno Porte: Estudo do Potencial de Aplicação de Tecnologias Simplificadas na Região do Semi-Árido Baiano. (Dissertação de Mestrado). Salvador: UFPBA, 149 p.

PROSAB - PROGRAMA DE SANEAMENTO BÁSICO. (1999). Metodologias e Técnicas de Minimização, Reciclagem e Reutilização de Resíduos Sólidos Urbanos. Rio de Janeiro - RJ, 65 p.

SCHALCH, V.; LEITE, W. C. A.; FERNANDES JÚNIOR, J. L.; CASTRO, M. C. A. A. (2002). Gestão e Gerenciamento de Resíduos Sólidos. Tese (Livre Docência). Escola de Engenharia de São Carlos Universidade de São Paulo.

TOZETTO, C. M. (2008). Modelagem Matemática de Aterros Sanitários com a Simulação Hidrológica da Geração de Lixiviado: Estudo de Caso do Aterro Sanitário de Curitiba. (Dissertação de Mestrado). Curitiba: UFPR - PR, 156p. 